\title{
UV-C Exposure Induces an Apoptosis-Like Process in Euglena gracilis
}

\author{
Michael J. Bumbulis and Brian M. Balog \\ Department of Biology and Geology, Baldwin Wallace University, 275 Eastland Road, Berea, OH 44017, USA \\ Correspondence should be addressed to Michael J. Bumbulis; mbumbuli@bw.edu
}

Received 4 December 2012; Accepted 27 December 2012

Academic Editors: A. Colanzi and M. Yamaguchi

Copyright ( 2013 M. J. Bumbulis and B. M. Balog. This is an open access article distributed under the Creative Commons Attribution License, which permits unrestricted use, distribution, and reproduction in any medium, provided the original work is properly cited.

\begin{abstract}
Euglena gracilis is a unicellular, free-living flagellate that inhabits various freshwater environments. Our research shows that exposure to UV-C light can trigger some form of programmed cell death. Cells exposed to UV-C light underwent delayed changes that were strongly reminiscent of apoptosis in mammalian cells, including cell shrinkage and DNA fragmentation that produced the characteristic ladder pattern commonly seen with apoptosis. DNA fragmentation could be inhibited by pretreatment with ZVAD-FMK and also independently induced by exposure to staurosporine. In addition, Euglena possess proteins that cross-reacted with antibodies raised against human caspases 3 and 9. Given that Euglena are extremely easy to culture and represent a lineage positioned near the base of the eukaryotic tree, they will be an excellent model system for comparative analyses with apoptotic-like death processes in other eukaryotic microbes.
\end{abstract}

\section{Introduction}

Apoptosis is a form of controlled cell death that is essential to animal life. This process plays a key role in embryological development, the homeostatic maintenance of organ systems, and the immune system $[1,2]$. Given that apoptosis is tightly linked to so many crucial cell-cell interactions, it is not surprising that it is universally distributed among metazoans. It has been well documented in mammals, insects, and nematodes, and there is good evidence for its existence in cnidarians $[3,4]$ and sponges $[5,6]$. In fact, both sponges and cnidarians possess caspases, the proteases that mediate apoptosis, and members of the $\mathrm{Bcl}-2$ superfamily. This would suggest that the apoptotic pathway was already well developed by the time metazoans appeared.

Because apoptosis would clearly impart an advantage in a multicellular context, allowing for the homeostatic control of cell numbers, it was originally believed to have coevolved with the appearance of metazoa. However, for more than a decade now, an apoptotic-like death process has been reported in a variety of unicellular organisms [7, 8]. Among these organisms, the process has been best described in Saccharomyces cerevisiae [9], where many of the characteristic cellular and biochemical changes associated with apoptosis $[1,2]$ have been detected: alterations in cell morphology (cell shrinkage), activation of a class of caspase-like proteases, externalization of membrane phosphatidylserine, condensation of the nucleus, and DNA fragmentation.

Among the protozoa, a programmed cell death process has been most extensively characterized in the group Euglenozoa, specifically the kinetoplasts [10]. Multiple studies have detected the characteristic apoptotic markers in both Leishmania and Trypanosoma which have been induced by a variety of factors, including hydrogen peroxide, starvation, heat shock, and staurosporine [8]. In addition, the process has also been shown to be calcium dependent in both species $[11,12]$. However, given their elaborate parasitic life cycles, and evidence that indicates Trypanosoma emerged late in evolution [13], it is possible this apoptotic-like process is a derived feature in kinetoplastids rather than ancestral for all euglenozoans. If it is an ancestral trait, we would expect to find evidence of a similar death process is the more distantly related Euglena.

UV light is known to induce apoptosis in wide variety of distantly related organisms, including mammals [14], reptiles [15], arthropods [16], nematodes [17], sponges [18], and 
yeast [19]. It has also been shown to induce programmed cell death in unicellular green algae $[20,21]$. Considering that UV light induces apoptosis in such a wide range of eukaryotes, and may even induce programmed cell death in cyanobacteria [22], it is reasonable to assume that such stress is a universal and, perhaps, the most ancient inducer of programmed cell death.

UV-B light has been reported to induce DNA degradation and cell morphology changes similar to apoptosis in Euglena gracilis [23]. However, no follow-up studies have been reported and while the DNA degradation was mediated by a metal-dependent nuclease and stimulated by calcium, the degradation was detected as simple DNA smearing on an electrophoresis gel rather than the laddering pattern indicative of fragmentation that is considered a hallmark of apoptosis. Here we confirm that an apoptotic-like cell death process does indeed occur in Euglena gracilis and is induced by UV light.

\section{Materials and Methods}

2.1. Cells and Culturing. Euglena gracilis (Carolina, NC, USA) was grown in soil media (Carolina, NC, USA) in a round bottom flask under a fluorescent light at room temperature supplemented with a sterilized pea. Cells were analyzed after growth for 3-4 weeks, reaching a typical density of $2 \times 10^{6}$ cells $/ \mathrm{mL}$ as estimated with a hemocytometer.

\subsection{DNA Isolation and Electrophoresis. DNA was isolated} from $5 \times 10^{6}$ cells using the QIAGEN (CA, USA) DNeasy Tissue Kit. The procedure for Cultured Animal cells was used with one modification: prior to adding the extract to a spin column, it was centrifuged at $2655 \times \mathrm{g}$ for $3 \mathrm{~min}$ and the resulting supernatant was transferred to the spin column. Approximately, $0.5 \mu \mathrm{g}$ of DNA was loaded onto a $2 \%$ agarose gel in TAE buffer and run at $60 \mathrm{~V}$ for 2 hour. Gels were stained with SYBR Green for 2 hours and visualized with a transilluminator.

\subsection{Death Experiments. The effect of UV exposure was tested} by placing $5 \times 10^{6}$ cells $40 \mathrm{~cm}$ from a Sylvania G3OT8 Germicidal Fluorescent Lamp $(253.7 \mathrm{~nm})$ with a UV output of 13.4 Watts for specified time increments. Cells were then left in the dark afterward for specified time periods. For inhibitor studies, Z-VAD-FMK was added to the cells to a final concentration of $20 \mu \mathrm{M}$ and preincubated for $30 \mathrm{~min}$. Cells were then exposed to UV light for thirty minutes and left in the dark for 18 hours before DNA isolation. For staurosporine experiments, a concentration of $1 \mu \mathrm{M}$ was used and DNA was isolated 18 hours after treatment.

2.4. Microscopic Analysis. Cells were visualized using an Olympus $\mathrm{BH}-2$ fluorescence microscope and images were captured with a Q Imaging Retiga 2000R camera. Cells were counted with a hemocytometer. To determine cell size, cells were fixed in ice-cold methanol for 15 minutes, centrifuged, resuspended in PBS, and the length and width of 100 cells were measured with a micrometer.

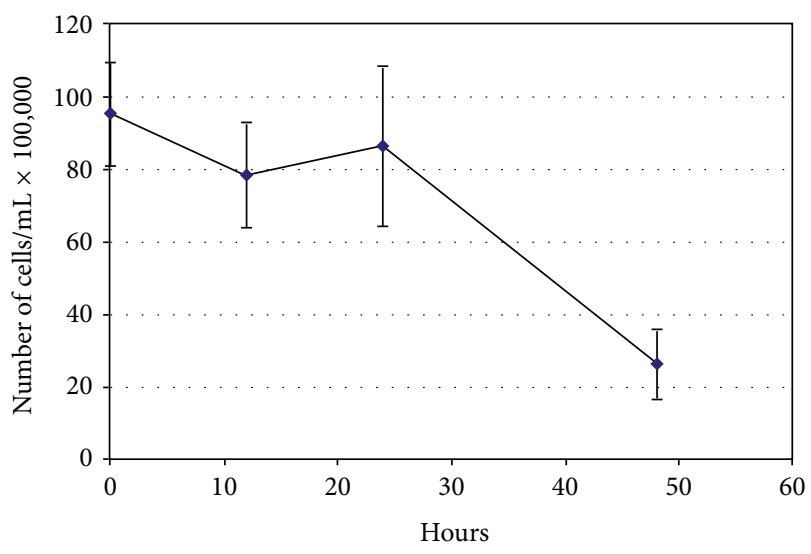

FIGURE 1: Cell numbers as a function of time after 30-minute UV exposure. The mean of three independent experiments is shown.

2.5. Western Blotting. Protein was isolated from 10 million cells according to Bumbulis et al. [24]. $20 \mu \mathrm{g}$ of protein was run on a $12 \%$ SDS polyacrylamide gel and then transferred to nitrocellulose. Blots were probed with polyclonal antibodies raised against caspases 3 and 9 (catalogue nos. 235412 and 218794, resp., Calbiochem). Bands were detected with using a chemiluminescence system (LumiGLO, KPL) and band density was determined with the Alpha DigiDoc RT software.

\section{Results}

To gauge the cytotoxic effects of UV light, cell motility was assayed after differing exposure times. A ten-minute exposure resulted as a loss of motility in $90 \%$ of the cells, while a 20-minute or more exposure resulted in a loss of motility among almost all cells. After the 30-minute exposure to UV, cell numbers were monitored for 48 hours. Cell numbers remained constant for the first 24 hours (Figure 1), but by 48 hours afterexposure, only $25 \%$ of the original population remained. This pattern indicates a delayed death response to UV light exposure.

Cell morphology was also analyzed as a consequence of UV light exposure. Two distinct abnormal shapes were detected: a slightly rounded cell with a massive central vacuole (Figure 2(c)) and a small, condensed cell with either an ovoid or spherical shape (Figures 2(a) and 2(b)). All abnormally shaped cells were immotile. The cells with vacuoles were seen immediately after exposure to UV light, where roughly $30 \%$ displayed this morphology one hour after exposure to UV light (Figure 3). Thereafter, such cells accounted for roughly $10 \%$ of the cells. By three hours afterexposure, the condensed, round and ovoid cells were most common (approximately $40 \%$ of cells) and by 24 hours afterexposure, represented $75 \%$ of the cells (Figure 3 ). The round/ovoid cells were determined to be smaller than normal cells. Whereas normal cells were measured to have a mean length of $66.4 \mu \mathrm{m}$ and a mean width of $14.2 \mu \mathrm{m}$, the rounded cells measured 28.2 and $19.32 \mu \mathrm{m}$, respectively.

To determine if these cellular changes were associated with DNA fragmentation, DNA was isolated from cells 


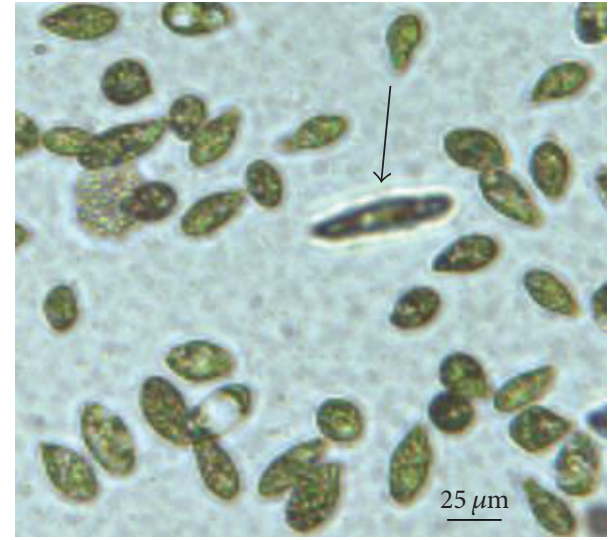

(a)

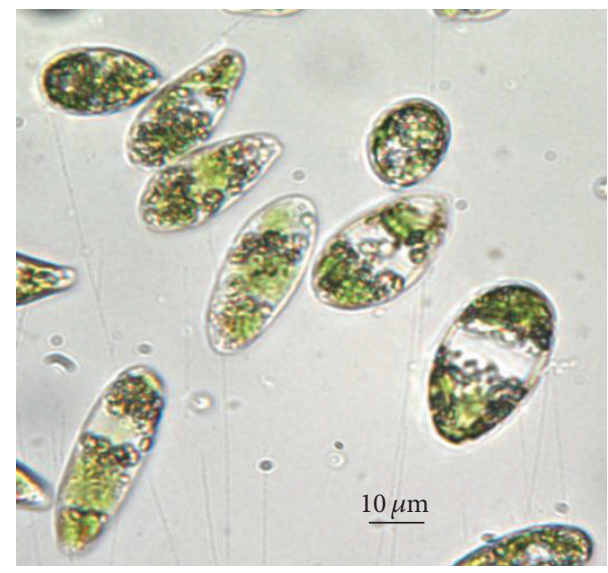

(c)

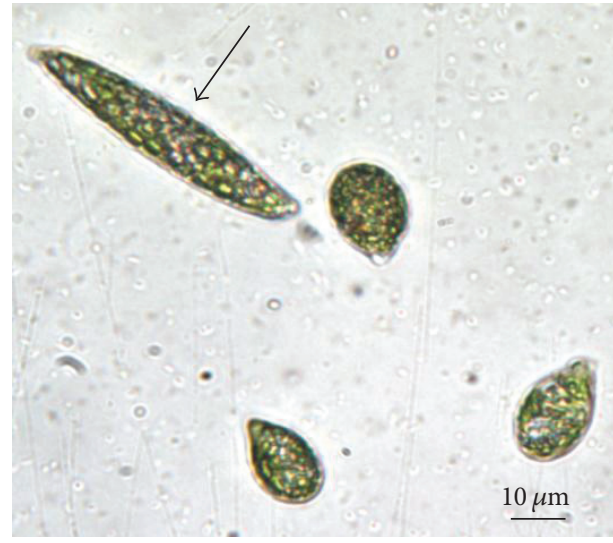

(b)

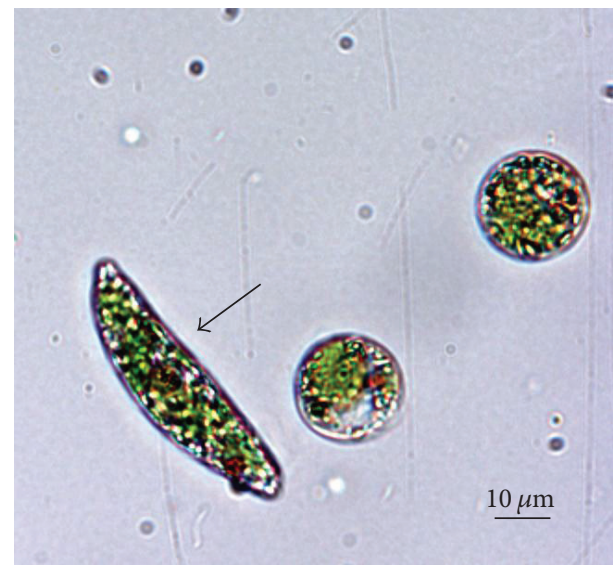

(d)

FIgURE 2: Cell morphology. (a) Cells 18 hours after exposure to 30 minutes of UV light, magnification 100x. (b) Cells 18 hours after exposure to 30 minutes of UV light, magnification 400x. (c) Cells 1 hour after exposure to 30 minutes of UV light magnification 400x. (d) Cells after 18 hours exposure to $1 \mathrm{mM}$ staurosporine. Arrows in (a), (b), and (d) all indicate normal cells.

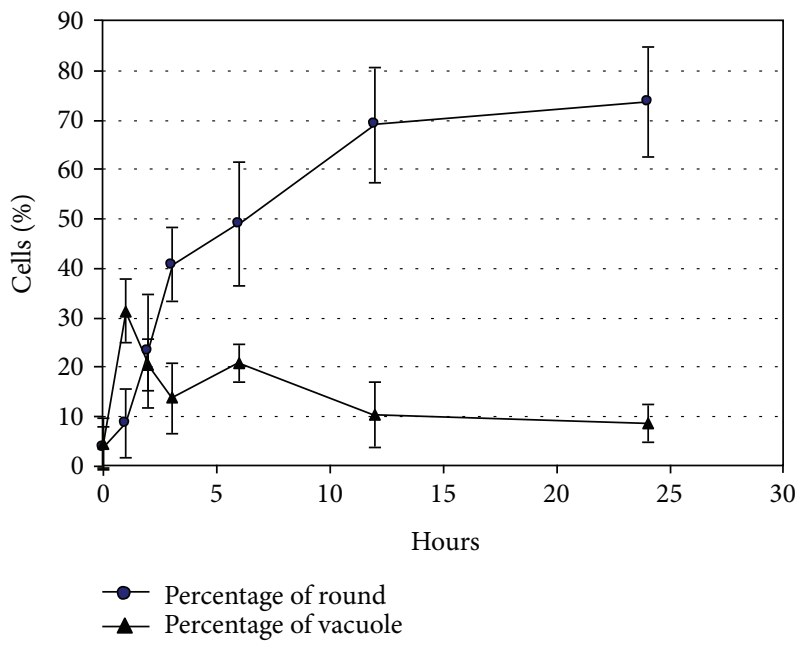

FIGURE 3: Cell morphology as a function of time after UV exposure. Data points represent mean from three independent experiments where one hundred cells were counted. exposed to UV light for differing periods of time. A clear pattern of fragmentation was seen after cells were exposed to UV light for 20 minutes and allowed to sit in the dark for 18 hours (Figure 4(a)). Several experiments showed that the 30-minute exposure more reproducibly produced this ladder pattern. The fragments differed in size by multiples of 180-200 bp. To determine when DNA fragmentation begins, cells were exposed to UV light for 30 minutes and then allowed to sit in the dark for different periods of time before the DNA was isolated. Figure 4(b) shows a faint ladder pattern 9 hours after UV exposure and by 12 hours, the ladder is quite distinct. Figure 4(c) shows that the DNA fragmentation was inhibited by treating cells with Z-VAD-FMK prior to UV light exposure (lanes 2 and 3 ).

Since Euglena was exhibiting signs of programmed cell death in response to UV light exposure, we decided to test further by determining whether staurosporine, an antibiotic known to induce apoptosis in human cells, would also trigger programmed cell death. As can be seen in Figure 4(c) (lane 4), 18 hours exposure to $1 \mu \mathrm{M}$ staurosporine did induce DNA 


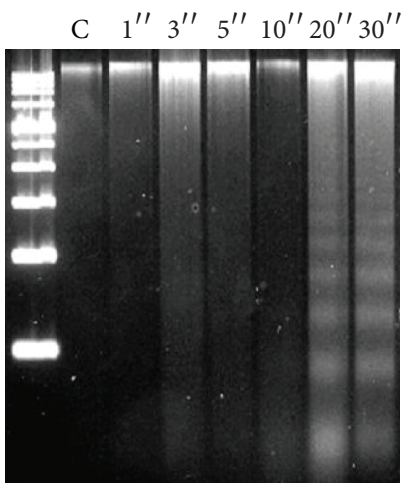

(a)

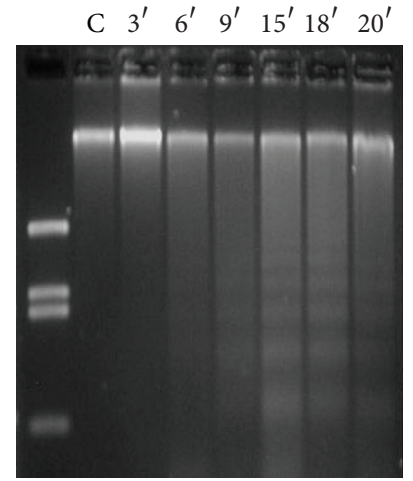

(b)

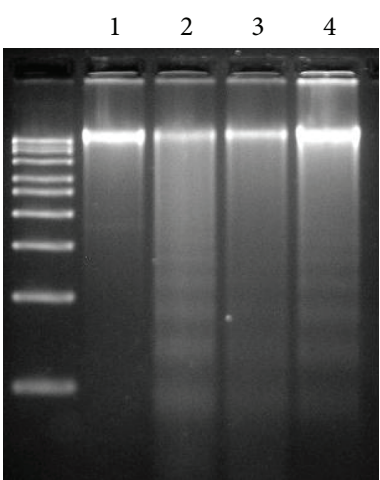

(c)

FIgure 4: Agarose gel electrophoresis. Markers for (a) and (c) are $1 \mathrm{~kb}$ ladder and pBR322 BstN1 cut for (b). (a) Cells exposed to UV for different times and allowed to sit in dark for 18 hours before DNA isolation. From left to right: control, $1 \mathrm{~min}, 3 \mathrm{~min}, 5 \mathrm{~min}, 10 \mathrm{~min}, 20 \mathrm{~min}$, and $30 \mathrm{~min}$. (b) Cells exposed to UV light for 30-minutes and DNA was isolated after sitting in dark for different time periods. From left to right: control, $3 \mathrm{hr}, 6 \mathrm{hr}, 9 \mathrm{hr}, 12 \mathrm{hr}, 15 \mathrm{hr}$, and $20 \mathrm{hr}$. (c) From left to right: (1) control; (2) 30-minute UV exposure and DNA isolated 18 hours later after sitting in dark; (3) preincubation with $20 \mu \mathrm{M}$ Z-VAD-FMK, then 30 minute UV exposure and DNA isolated 18 hours later after sitting in dark; (4) treated with $1 \mu \mathrm{M}$ staurosporine and DNA isolated 18 hours later.

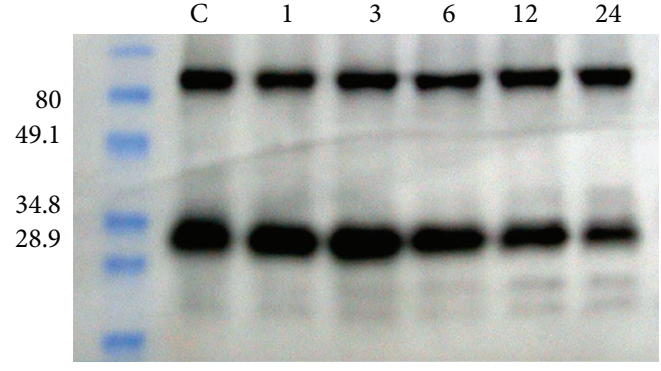

(a)

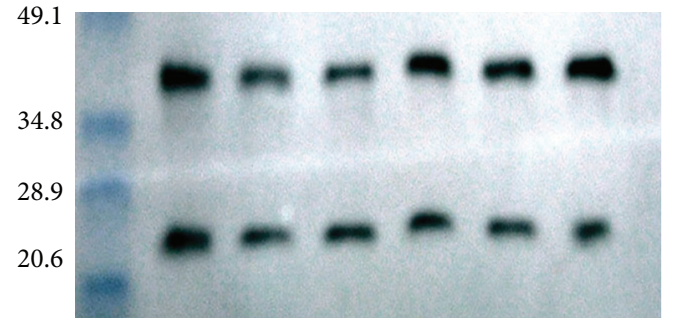

(b)

FIGURE 5: Western blot showing cross-reactions of whole-cell protein extracts from Euglena gracilis with antibodies raised against human caspases 3 (a) and 9 (b). Lanes on left (C) represent protein from cells not exposed to UV light. Remaining lanes are from cells exposed to UV light for 30 minutes and protein was isolated 1, 3, 6, 12, and 24 hours after exposure. Protein size markers are shown in far left lane with blue bands.

fragmentation. Also at this time, most cells were immotile and almost perfectly spherical (Figure 2(d)).

Caspase 3 immunoreactivity was evident as two major bands with a molecular mass of 82 and $33 \mathrm{kD}$ (Figure $5(\mathrm{a})$ ). Between 3 and 6 hours after exposure to UV light, two bands, corresponding to a molecular mass of 22 and $18 \mathrm{kD}$, become distinct. Furthermore, by 24 hours post-UV exposure, the $33 \mathrm{kD}$ band had lost $65 \%$ of its intensity compared to 3 hours post-UV exposure. These data suggest posttranslational modification consistent with protease activation. Caspase 9 also displayed immunoreactivity, as evidenced by two major bands with a molecular mass of 42 and $24 \mathrm{kD}$ (Figure 5(b)). However, no evidence of posttranslational modification was seen.

\section{Discussion}

Exposure to the UV-B light was previously shown to induce cell death in Euglena. Cells became round and metal iondependent DNA degradation was reported [23]. However, the electrophoretic data showed a smearing pattern rather than a ladder pattern that is the hallmark of apoptosis. Given the ambiguity of these data, with respect to whether or not the death was apoptotic-like, it is not surprising that Euglena have not been cited as an example in any published review on unicellular programmed cell death. Here we show that exposure to UV-C light induced cell death and confirm that this death process is very similar to apoptosis. We were able to detect a DNA ladder pattern that appeared 6-9 hours after exposure to UV. The fragments differed in size by approximately $180 \mathrm{bp}$, which is consistent with earlier research that isolated all five histones from Euglena [25] and detected a typical nucleosome pattern in the chromosomes [26]. UV treatment also induced cell morphology changes consistent with programmed cell death. Immediately following UV exposure, a large vacuole-like structure appeared near the center of the cell. This trait was evident in numerous cells for the first 3 hours and its incidence declined thereafter. It is unlikely that this was a precursor to lysis, as actual cell numbers did not begin to decline until 24 hours after 
UV exposure, long after this vacuole-like state became rare. Instead, a small, rounded, morphology began to predominate after 3 hours and constituted almost 75\% of cells by 24 hours after exposure. As noted above, these cells were measured to be smaller than normal cells.

Caspase-like activity appears to be involved in Euglena's cell death. First, the DNA fragmentation pattern seen after UV exposure was inhibited by pretreatment with Z-VADFMK, a known caspase inhibitor. Because Z-VAD-FMK had successfully inhibited DNA fragmentation, we set out to detect caspase-like proteins using western blots. We probed with polyclonal antibodies raised against human caspases previously reported to cross-link with proteins from Dunaliella tertiolecta, a green algae also reported to undergo programmed cell death in response to light deprivation [27]. We successfully detected a cross-reaction using antibodies raised against caspases 3 and 9. Caspase 3, but not 9, showed evidence of a posttranslational modification approximately 6-9 hours after UV exposure. Given their distant relationship, it is remarkable that the pattern we detected for caspase 3 was very similar to that seen in $D$. tertiolecta. In $D$. tertiolecta, there are two primary bands corresponding to molecular mass of 70 and $30 \mathrm{kD}$ and a smaller band around $18 \mathrm{kD}$ appears after 5 days in of darkness. With Euglena, there are two primary bands corresponding to MW of 82 and $33 \mathrm{kD}$ and smaller bands, 18 and $22 \mathrm{kD}$, appear after 6 hours of UV exposure.

Because the DNA fragmentation pattern was inhibited by Z-VAD-FMK and a Euglena protein was bounded by antibodies raised against human caspase 3 , we decided to test if the antibiotic staurosporine could also induce programmed cell death. Staurosporine has been reported to induce apoptosis in human cell lines through a pathway that involves the activation of caspase 3 [28-30]. We were able to show that by 18 hours posttreatment, most cells were immotile and round and their DNA showed a DNA ladder pattern, evidence that this drug also induces an apoptotic-like death process. Future studies are currently underway to better characterize Euglena's response to staurosporine.

Current studies on programmed cell death in unicellular organisms are still largely in the detection and characterization stage. But because Euglenoids are positioned near the base of the eukaryotic evolutionary tree, the detection of programmed cell death in Euglena should be of great help in understanding the evolution of apoptosis by opening the door to informative comparative analyses between species. First, programmed cell death in kinetoplasts has been extensively studied. By comparing the cell death processes in Euglena and the trypanosomes, for example, we may better understand how the programmed cell death processes and machinery adapted as the lineage that led to trypanosomes adopted an obligate parasitic lifestyle. Second, programmed cell death has now been reported and described in more than one species of green algae. A comparison between Euglena and green algae could look for similarities. This would help us to better reconstruct the state of programmed cell death in the last common ancestor of Euglena and green algae, which in turn would get us closer to the last common ancestor of all Eukaryotes.

\section{Conflict of Interests}

The authors declare that they have no conflict of interests.

\section{Acknowledgments}

This work was made possible by Baldwin Wallace University's in-house funding through its Research Costs Grant.

\section{References}

[1] A. Lawen, "Apoptosis-an introduction," BioEssays, vol. 25, no. 9, pp. 888-896, 2003.

[2] C. Potten and J. Wilson, Apoptosis: The Life and Death of Cells, Cambridge University Press, Cambridge, UK, 2004.

[3] M. Cikala, B. Wilm, E. Hobmayer, A. Böttger, and C. N. David, "Identification of caspases and apoptosis in the simple metazoan Hydra," Current Biology, vol. 9, no. 17, pp. 959-962, 1999.

[4] A. Böttger and O. Alexandrova, "Programmed cell death in Hydra," Seminars in Cancer Biology, vol. 17, no. 2, pp. 134-146, 2007.

[5] M. Wiens, A. Krasko, C. I. Müller, and W. E. G. Müller, "Molecular evolution of apoptotic pathways: cloning of key domains from sponges (Bcl-2 homology domains and death domains) and their phylogenetic relationships," Journal of Molecular Evolution, vol. 50, no. 6, pp. 520-531, 2000.

[6] M. Wiens, A. Krasko, S. Perovic, and W. E. G. Müller, "Caspasemediated apoptosis in sponges: cloning and function of the phylogenetic oldest apoptotic proteases from metazoa," Biochimica et Biophysica Acta, vol. 1593, no. 2-3, pp. 179-189, 2003.

[7] A. V. Gordeeva, Y. A. Labas, and R. A. Zvyagilskaya, "Apoptosis in unicellular organisms: mechanisms and evolution," Biochemistry, vol. 69, no. 10, pp. 1055-1066, 2004.

[8] M. Deponte, "Programmed cell death in protists," Biochimica et Biophysica Acta, vol. 1783, no. 7, pp. 1396-1405, 2008.

[9] F. Madeo, E. Herker, S. Wissing, H. Jungwirth, T. Eisenberg, and K. U. Fröhlich, "Apoptosis in yeast," Current Opinion in Microbiology, vol. 7, pp. 655-660, 2004.

[10] A. Debrabant, N. Lee, S. Bertholet, R. Duncan, and H. L. Nakhasi, "Programmed cell death in trypanosomatids and other unicellular organisms," International Journal for Parasitology, vol. 33, no. 3, pp. 257-267, 2003.

[11] E. L. Ridgley, Z. H. Xiong, and L. Ruben, "Reactive oxygen species activate a $\mathrm{Ca}^{2+}$-dependent cell death pathway in the unicellular organism Trypanosoma brucei brucei," Biochemical Journal, vol. 340, no. 1, pp. 33-40, 1999.

[12] S. B. Mukherjee, M. Das, G. Sudhandiran, and C. Shaha, "Increase in cytosolic $\mathrm{Ca}^{2+}$ levels through the activation of nonselective cation channels induced by oxidative stress causes mitochondrial depolarization leading to apoptosis-like death in Leishmania donovani promastigotes," The Journal of Biological Chemistry, vol. 277, no. 27, pp. 24717-24727, 2002.

[13] A. G. B. Simpson, E. E. Gill, H. A. Callahan, R. W. Litaker, and A. J. Roger, "Early evolution within kinetoplastids (Euglenozoa), and the late emergence of trypanosomatids," Protist, vol. 155, no. 4, pp. 407-422, 2004.

[14] G. Li, J. A. Bush, and V. C. Ho, "Effect of retinoic acid on apoptosis and DNA repair in human keratinocytes after UVB irradiation," Journal of Cutaneous Medicine and Surgery, vol. 4, no. 1, pp. 2-7, 2000. 
[15] E. B. Sorensen and P. W. Mesner, "IgH-2 cells: a reptilian model for apoptotic studies," Comparative Biochemistry and Physiology, vol. 140, no. 1, pp. 163-170, 2005.

[16] M. A. Menze, G. Fortner, S. Nag, and S. C. Hand, "Mechanisms of apoptosis in crustacea: what conditions induce versus suppress cell death?" Apoptosis, vol. 15, no. 3, pp. 293-312, 2010.

[17] L. Stergiou, R. Eberhard, K. Doukoumetzidis, and M. O. Hengartner, "NER and HR pathways act sequentially to promote UV-C-induced germ cell apoptosis in Caenorhabditis elegans," Cell Death and Differentiation, vol. 18, no. 5, pp. 897-906, 2011.

[18] W. E. G. Müller, H. Ushijima, R. Batel et al., "Novel mechanism for the radiation-induced bystander effect: nitric oxide and ethylene determine the response in sponge cells," Mutation Research - Fundamental and Molecular Mechanisms of Mutagenesis, vol. 597, no. 1-2, pp. 62-72, 2006.

[19] R. Del Carratore, C. Della Croce, M. Simili, E. Taccini, M. Scavuzzo, and S. Sbrana, "Cell cycle and morphological alterations as indicative of apoptosis promoted by UV irradiation in $S$. cerevisiae," Mutation Research, vol. 513, no. 1-2, pp. 183-191, 2002.

[20] S. Moharikar, J. S. D’Souza, A. B. Kulkarni, and B. J. Rao, "Apoptotic-like cell death pathway is induced in unicellular chlorophyte Chlamydomonas reinhardtii (Chlorophyceae) cells following UV irradiation: detection and functional analyses," Journal of Phycology, vol. 42, no. 2, pp. 423-433, 2006.

[21] C. Jiménez, J. M. Capasso, C. L. Edelstein et al., "Different ways to die: cell death modes of the unicellular chlorophyte Dunaliella viridis exposed to various environmental stresses are mediated by the caspase-like activity DEVDase," Journal of Experimental Botany, vol. 60, no. 3, pp. 815-828, 2009.

[22] S. P. Singh, D. P. Häder, and R. P. Sinha, "Cyanobacteria and ultraviolet radiation (UVR) stress: mitigation strategies," Ageing Research Reviews, vol. 9, no. 2, pp. 79-90, 2010.

[23] R. Scheuerlein, S. Treml, B. Thar, U. K. Tirlapur, and D. P. Hader, "Evidence for UV-B-induced DNA degradation in Euglena gracilis mediated by activation of metal-dependent nucleases," Journal of Photochemistry and Photobiology B, vol. 31, no. 3, pp. 113-123, 1995.

[24] M. J. Bumbulis, G. Wroblewski, D. McKean, and D. R. Setzer, "Genetic analysis of Xenopus transcription factor IIIA," Journal of Molecular Biology, vol. 284, no. 5, pp. 1307-1322, 1998.

[25] N. J. Jardine and J. L. Leaver, "The fractionation of histones isolated from Euglena gracilis," Biochemical Journal, vol. 169, no. 1, pp. 103-111, 1978.

[26] S. Delpech, M. H. Bre, A. Mazen et al., "Electron microscopic visualization of nucleosomal organization in B12 starved and control Euglena chromatin," Cell Biology International Reports, vol. 6, no. 2, pp. 197-203, 1982.

[27] M. Segovia, L. Haramaty, J. A. Berges, and P. G. Falkowski, "Cell death in the unicellular chlorophyte Dunaliella tertiolecta. A hypothesis on the evolution of apoptosis in higher plants and metazoans," Plant Physiology, vol. 132, no. 1, pp. 99-105, 2003.

[28] G. Preta and B. Fadeel, "Scythe cleavage during Fas (APO-1)and staurosporine-mediated apoptosis," FEBS Letters, vol. 586, no. 6, pp. 747-752, 2012.

[29] D. M. Kovacs, R. Mancini, J. Henderson et al., "Staurosporineinduced activation of caspase- 3 is potentiated by presenilin 1 familial Alzheimer's disease mutations in human neuroglioma cells," Journal of Neurochemistry, vol. 73, no. 6, pp. 2278-2285, 1999.
[30] H. J. Chae, J. S. Kang, J. O. Byun et al., "Molecular mechanism of staurosporine-induced apoptosis in osteoblasts," Pharmacological Research, vol. 42, no. 4, pp. 373-381, 2000. 

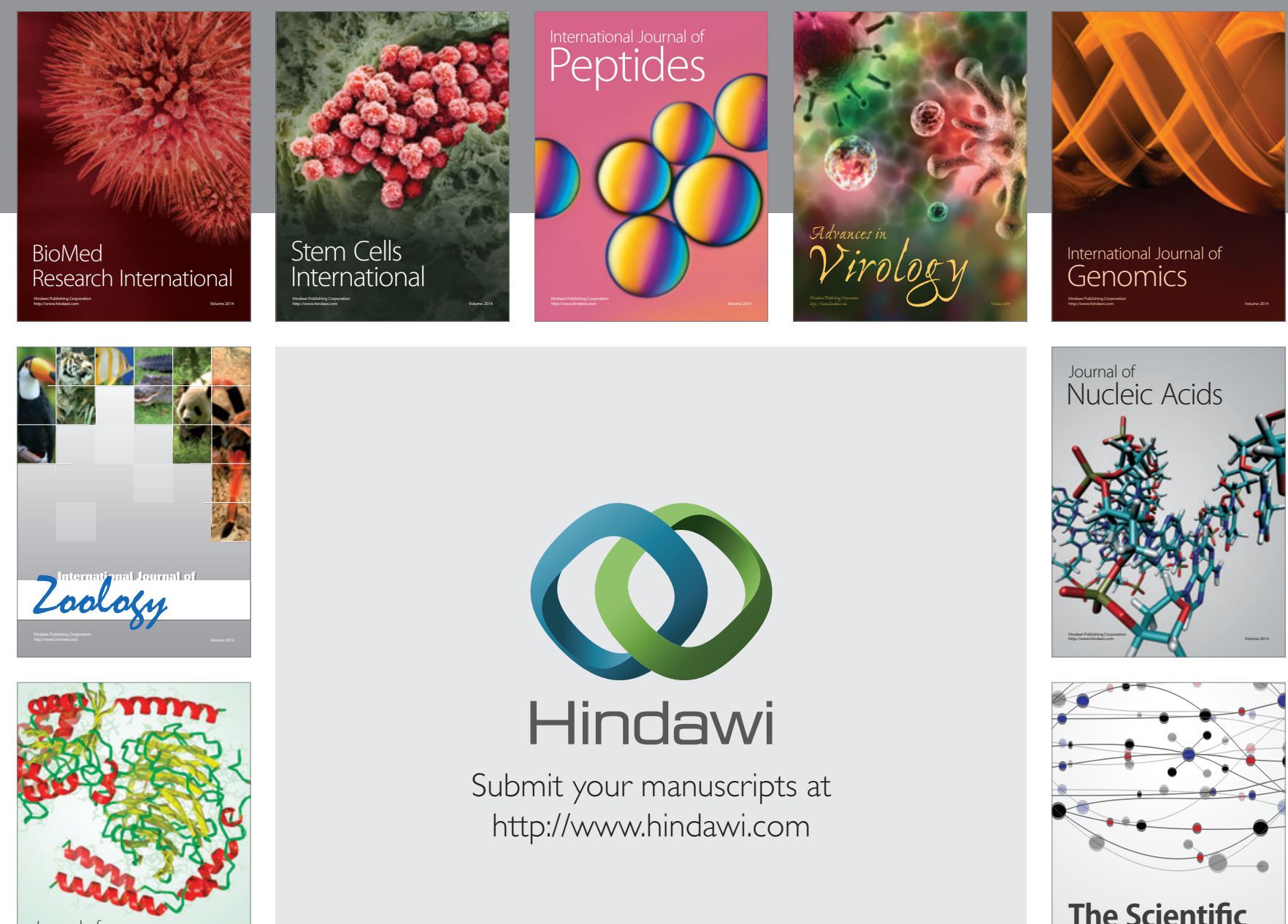

Submit your manuscripts at

http://www.hindawi.com

Journal of
Signal Transduction
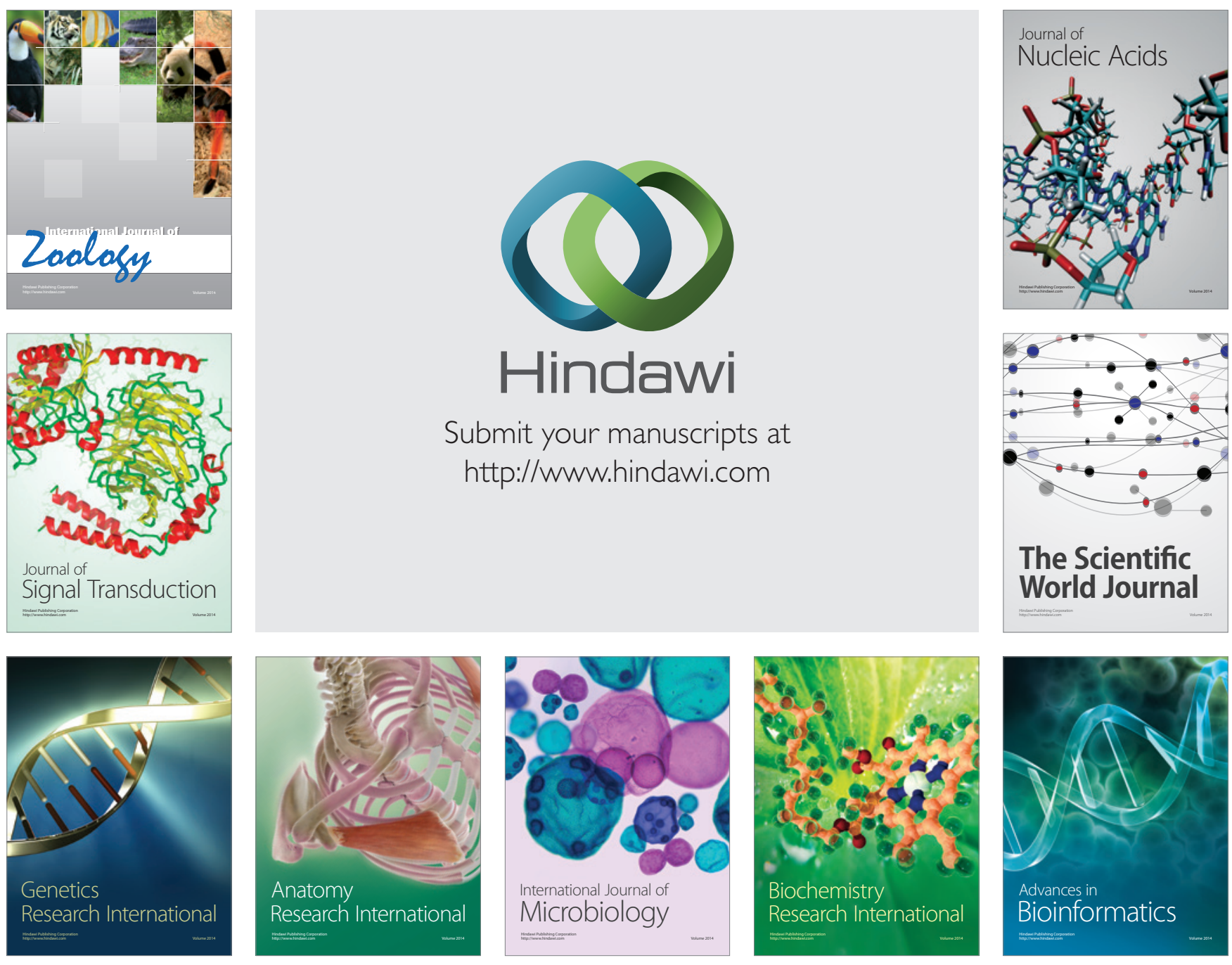

The Scientific World Journal
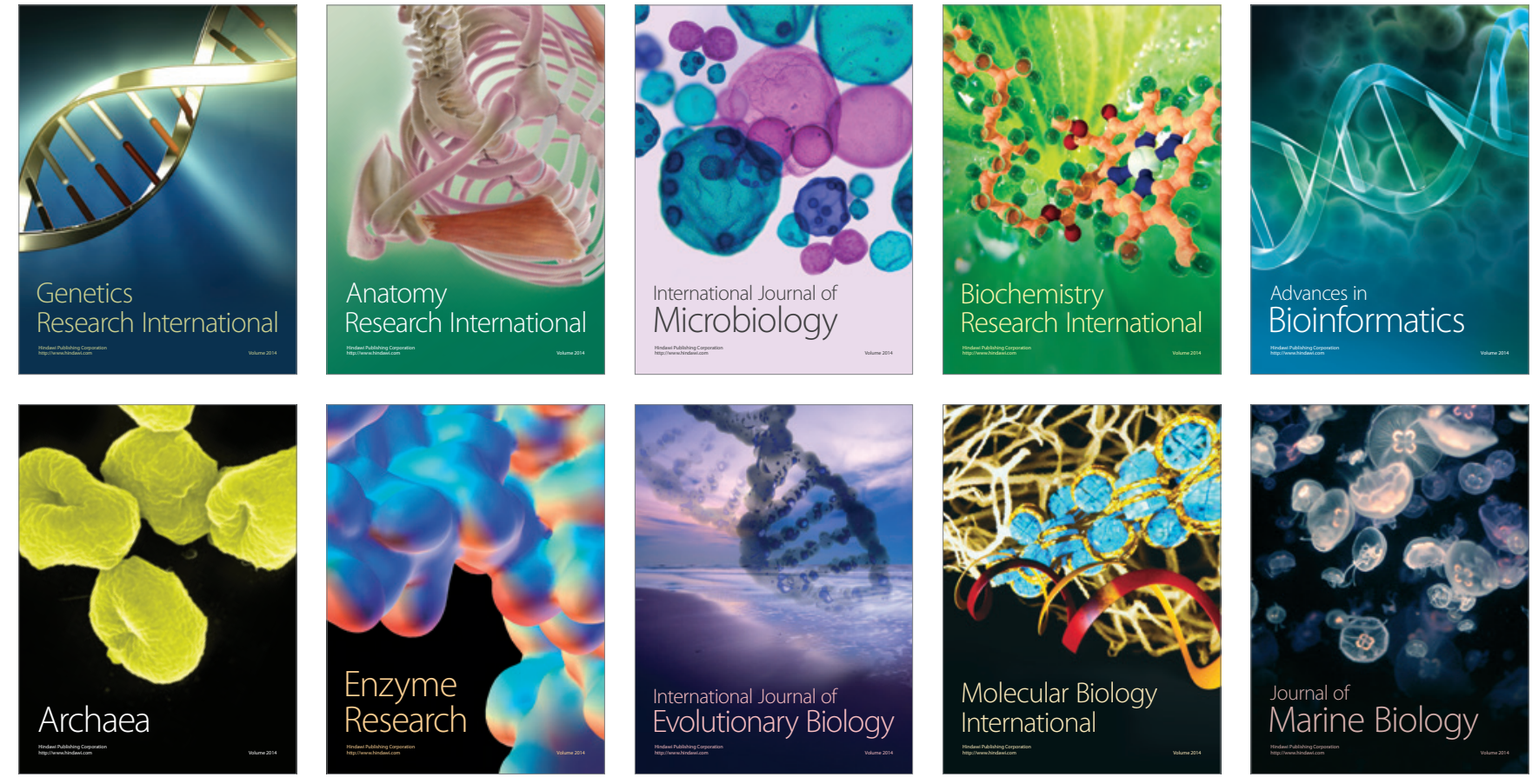